desenvolvida de acordo com a declaração Preferred Reporting Items for Systematic Reviews and Meta-Analyses. Foi executado e registado um protocolo de pesquisa no International Prospective Register of Systematic Reviews. O estudo foi orientado pela seguinte questão de investigação: A clorexidina, como agente antissético integrado na rotina de higiene oral dos pacientes internados em Unidades de Cuidados Intensivos, é eficaz na prevenção da Pneumonia Associada à Ventilação?. A pesquisa foi realizada nas bases de dados Cochrane CENTRAL, PubMed ${ }^{\circledR}$, Web of ScienceTM, ScienceDirect e Dentistry and Oral Sciences Sources. O processo de seleção de artigos decorreu em duas fases, de forma independente, por dois avaliadores. Os títulos e os resumos dos artigos resultantes da remoção de duplicados foram avaliados e depois foi feita a análise do texto integral dos artigos selecionados. Resultados: O processo de seleção resultou em 10 artigos, dos quais 6 ensaios clínicos randomizados, 2 estudos longitudinais, 1 estudo transversal e 1 estudo quase-experimental. Todos analisaram de forma direta a influência da clorexidina e das intervenções comparativas na incidência da Pneumonia Associada à Ventilação, sendo que dois concluíram que o colutório de clorexidina a $0,2 \%$ era eficaz na redução da incidência da Pneumonia Associada à Ventilação, um concluiu o mesmo para uma concentração de $2 \%$ de clorexidina e outro concluiu que a clorexidina apresentava menor eficácia que a intervenção comparativa, de forma estatisticamente significativa. Dos restantes 6 estudos, que obtiveram resultados sem significância estatística, quatro constataram a eficácia da clorexidina na redução da incidência de Pneumonia Associada à Ventilação e dois verificaram que a clorexidina era menos eficaz que a intervenção comparativa para esse propósito. Conclusões: A clorexidina assume-se como um agente de higiene oral potencialmente eficaz na prevenção da Pneumonia Associada à Ventilação em Unidades de Cuidados Intensivos.

http://doi.org/10.24873/j.rpemd.2022.01.930

\section{\#074 Os efeitos biológicos das resinas 3D usadas em Medicina Dentária: Revisão sistemática CrossMark}

Anabela Paula*, Inês Alexandre Neves Francisco, Madalena Prata Ribeiro, Carlos Miguel Marto, Eunice Virgínia Carrilho, Francisco Vale

Instituto de Ortodontia da Faculdade de Medicina da Universidade de Coimbra, Instituto de Clínica Integrada da Faculdade de Medicina da Universidade de Coimbra

Objetivos: Os dispositivos médico-dentários termoplásticos têm sido utilizados de forma crescente nos últimos anos após o aparecimento das tecnologias digitais. Na Ortodontia, as terapêuticas com alinhadores têm ganho maior destaque, especialmente devido às políticas agressivas de promoção desenvolvidas pela indústria. No entanto, os seus efeitos sistémicos não são conhecidos e existem poucos estudos sobre a avaliação da toxicidade sistémica destes materiais. A libertação de bisfenol A e outros monómeros residuais têm efeitos citotóxicos, genotóxicos e estrogénicos. O objetivo desta revisão sistemática é analisar sistematicamente a qualidade da evidência existente quer em estudos in vitro, quer em estudos clínicos. Materiais e métodos: A questão PICO formulada foi ' A utilização de dispositivos resinosos 3D induz efeitos citotóxicos ou alterações dos níveis de estrogénios?". A pesquisa foi realizada em várias bases de dados e segundo as normas PRISMA. Foram incluídos estudos in vitro, in vivo e clínicos. O risco de viés foi avaliado através das ferramentas da Cochrane. A avaliação da qualidade da evidência foi realizada através da ferramenta GRADE. Resultados: Um total de 236 artigos pesquisados em várias bases de dados foram inicialmente escrutinados. O risco de viés foi considerado médio a baixo. A análise da qualidade da evidência foi considerada baixa a média. Conclusões: Os efeitos citotóxicos ou nos níveis de estrogénios não pode ser confirmada com base na evidência preliminar limitada dada pelos estudos in vitro. A evidência de libertação de bisfenol A e outros monómeros dos dispositivos termoplásticos, quer nos estudos in vitro, quer nos estudos clínicos, mantêm-se ambígua. Os resultados poucos robustos da literatura atual demonstram a absoluta necessidade de mais estudos, especialmente devido às eventuais implicações sobre a fertilidade de doentes jovens, uma vez que constituem um dos maiores grupos portadores destas terapêuticas ortodônticas. http://doi.org/10.24873/j.rpemd.2022.01.931

\section{\#075 Comportamento de iões metálicos cromo} e cobalto - Coeficientes de difusão mútua

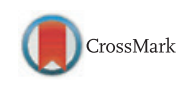

Sónia Fangaia*, Ana Cristina Ribeiro, Artur Valente, Miguel Esteso, Fernando Guerra, Pedro Nicolau

Departamento de Química da Universidade de Coimbra, Universidade Católica Santa Teresa de Jésus de Ávila - Espanha, Instituto de Implantologia e Prostodontia Faculdade de Medicina da Universidade de Coimbra

Objetivos: Estudar os coeficientes de difusão dos iões cromo e cobalto sob a forma de sais, presentes nas próteses dentárias, em meios com diferentes $\mathrm{pH}$, nomeadamente saliva artificial com $\mathrm{pH}=7,0 ; 8,3$ e 2.3 e saliva artificial fluoretada com $\mathrm{pH}=7,0$ e 2,3. Materiais e métodos: Soluções contendo cloreto de cobalto (II) hexa-hidratado (Sigma-Aldrich ${ }^{\circledR}$ ) pró-análise e cloreto de cromo (III) hexa-hidrato (Riedel-de-Haen ${ }^{\circledR}$ ) pró-análise com uma pureza (fração de massa)> 0,99 e 0,97 , respetivamente foram usados sem mais purificação. Estas soluções para as medidas dos coeficientes de difusão foram preparadas com água Millipore-Q (resistência específica $=1,82 \times 105 \Omega \mathrm{m}$, a $298,15 \mathrm{~K}$ ). Todas as soluções foram preparadas e usadas imediatamente, a 298,15 K em cada ensaio. Utilizou-se um modelo experimental pseudo-binário, baseado na técnica de dispersão de Taylor em que se faz uma injeção de um pequeno volume de cada solução, contendo o solvente (saliva artificial com $\mathrm{pH}=7,0,8,3$ e 2.3; e saliva artificial fluoretada com $\mathrm{pH}=7,0$ e 2,3) e o soluto, neste caso ião/ iões a analisar; nesse solvente em fluxo laminar através de um longo tubo capilar. Após a injeção, o pulso é disperso pela ação do gradiente de concentração e devido ao perfil parabólico de velocidades do eluente. Os resultados são medidos por um refratómetro diferencial e o tratamento matemático dos dados é baseado na 2. ${ }^{\text {a }}$ lei de Fick. Resultados: Em saliva artificial com pH=2,3, com ácido láctico, ou fluoreto de sódio, 